\title{
Prevalence, genotyping and risk factors of Giardia duodenalis from dogs in Vietnam
}

\author{
Sam Thi NGUYEN ${ }^{1)}$, Yasuhiro FUKUDA ${ }^{4)}$, Duc Tan NGUYEN ${ }^{1)}$, Ha Thanh DAO2), \\ Duc Quyet LE $^{1)}$, Khanh Linh BUI ${ }^{3)}$, Chika TADA ${ }^{4)}$ and Yutaka NAKAI ${ }^{4) *}$ \\ ${ }^{1)}$ Department of Parasitology, Central Vietnam Veterinary Institute, km4 Dongde street, Nhatrang 650000, \\ Vietnam \\ ${ }^{2)}$ National Institute of Veterinary Research, No 86, Truong Chinh street, Hanoi 100000, Vietnam \\ 3) Parasitology Department, Vietnam National University of Agricultural, Hanoi 100000, Vietnam \\ 4)Laboratory of Sustainable Animal Environmental, Graduate School of Agricultural Science, Tohoku University, \\ Naruko-Onsen, Osaki, Miyagi 989-6711, Japan
}

J. Vet. Med. Sci.

80(1): 92-97, 2018

doi: 10.1292/jvms.17-0498

Received: 6 September 2017 Accepted: 26 October 2017

Published online in J-STAGE: 29 November 2017
ABSTRACT. This study was carried out to determine the prevalence, genotypes/assemblages and possible risk factors associated with Giardia duodenalis infection in dogs in central Vietnam. A total of 209 dog fecal samples, randomly collected from private owned dogs $(n=105)$ and dogs from stores ( $n=104)$, were examined for Giardia cysts by microscopy. Positive samples were genotyped by PCR-sequence analysis of $\beta$-giardin and triosephosphate isomerase genes markers. Risk factors were studied using a structured questionnaire and collected data were analyzed by univariate and multivariate logistic regression analyses. Results indicated that the overall infection rate was $8.6 \%(18 / 209)$ with the detected parasites were belonging to the non-zoonotic assemblages $C$ and D. Age, gender and origin of animals were the main risk factors associated with G. duodenalis infection in dogs under study. Occurrence of infection was more likely in young animals compared to old ones and in females compared to males. Dogs originated from stores were more prone to Giardia infection compared to private owned counterparts.

KEY WORDS: dog, genotyping, Giardia, risk assessment

Giardia duodenalis (syn. Giardia intestinalis, Giardia lamblia) is a ubiquitous enteric protozoan parasite that infects a wide range of vertebrate hosts [3]. The infection is transmitted by the fecal-oral route via ingestion of the infective cysts through contaminated food and/or water [3]. The course of the disease is highly variable, ranging from asymptomatic infection to acute or chronic illness with diarrhea [10]. In human, G. duodenalis is frequently associated with outbreaks and sporadic cases [20], with estimation of 500,000 annual infections worldwide, mostly in children in Asia, Africa and Latin America [26].

Giardiasis is common in dogs, with infection rate ranging from 5-70\% [3]. Of the eight genotypes/assemblages (A to $\mathrm{H}$ ), that have been recognized within $G$. duodenalis complex species, assemblages $\mathrm{C}$ and D are canine-specific, however assemblages A, B and $\mathrm{E}$ were also reported [9, 20].

In Vietnam, molecular studies were focused on G. duodenalis in cattle [4, 13], with obvious scarcity of data from other hosts. Vietnamese people are usually raising dogs for the purpose of house-keeping and as companion animals. Although dogs in such situations are in close contact with humans, no data are available on the occurrence and identity of Giardia parasites in such dogs. Therefore, the present study was designed to investigate the prevalence and risk factors of Giardia infection in dogs in Vietnam, and molecularly characterize the obtained isolates up to assemblage level, thereby to assess the zoonotic potential of the detected parasites.

\section{MATERIALS AND METHODS}

\section{Collection of samples}

During the period from October 2016 to March 2017, a total of 209 fecal samples were collected from dogs in DacLac ( $\mathrm{n}=111$ ) and KhanhHoa $(n=98)$ provinces, including private owned dogs $(n=105)$ and dogs in stores $(n=104)$. The dog population was divided into three age groups: $<12$ months $(n=73), 12-36$ months $(n=92)$ and $>36$ months $(n=44)$. For private owned dogs, animals were living indoors and had the chance of controlled roaming outside once or twice a day. For dogs from stores, animals were kept in metal kennels with supplementary food. In fact, dogs in stores are not always kept in individual cages, each metal cage usually contains from 1-2 heads, depending on convenience of the cage. Sampled dogs were Vietnamese native breed, native cross breed

*Correspondence to: Nakai, Y.: yutaka.nakai.d1@tohoku.ac.jp

O2018 The Japanese Society of Veterinary Science

This is an open-access article distributed under the terms of the Creative Commons Attribution Non-Commercial No Derivatives (by-nc-nd) License. (CC-BY-NC-ND 4.0: https://creativecommons.org/licenses/by-nc-nd/4.0/) 
Table 1. Univariate analysis of factors predicted to be associated with the presence of Giardia duodenalis in dogs in central Vietnam

\begin{tabular}{|c|c|c|c|}
\hline Factor & $n$ & No positive (\%) & $P$-value \\
\hline Location (province) & & & 0.441 \\
\hline KhanhHoa & 98 & $10(10.2)$ & \\
\hline DacLac & 111 & $8(7.2)$ & \\
\hline Age (months) & & & 0.019 \\
\hline$<12$ & 73 & $12(16.4)$ & \\
\hline $12-36$ & 92 & $4(4.3)$ & \\
\hline$>36$ & 44 & $2(4.5)$ & \\
\hline Gender of animals & & & 0.038 \\
\hline Male & 107 & $5(4.7)$ & \\
\hline Female & 102 & $13(12.7)$ & \\
\hline Breed of animals & & & 0.214 \\
\hline Japanese crossed & 12 & $0(0)$ & \\
\hline Germanic crossed & 5 & $0(0)$ & \\
\hline Vietnamese native pure & 135 & $16(11.9)$ & \\
\hline Mixed & 57 & $2(3.5)$ & \\
\hline Clinical signs (Diarrhea) & & & 0.081 \\
\hline Yes & 31 & $0(0)$ & \\
\hline No & 178 & $18(10.1)$ & \\
\hline Sterilized status & & & 0.39 \\
\hline Yes & 20 & $3(15.0)$ & \\
\hline No & 189 & $15(7.9)$ & \\
\hline Origins of animals & & & 0.046 \\
\hline Private owned & 105 & $5(4.8)$ & \\
\hline Stores & 104 & $13(12.5)$ & \\
\hline Environmental conditions & & & 0.293 \\
\hline Urban area & 150 & $11(7.3)$ & \\
\hline Suburban area & 59 & $7(11.9)$ & \\
\hline
\end{tabular}

with Japanese and native cross breed with Germanic dogs along with mixed unknown breed(s) (Table 1). Fecal samples were collected from the floor immediately after defecation in the morning, placed in individual plastic bags, kept at $4-8^{\circ} \mathrm{C}$ and processed within 2-4 days after collection.

Individual animal information was obtained from the owner of the animal and the master of the store, through a designed questionnaire. The questionnaire addressed the following points: the age and clinical status of the animals, the gender, breed of dogs and sterilized status, the origin of the animals and environmental conditions of dogs. The protocol of the present study was approved by the Scientific Committee of Central Vietnam Veterinary Institute. No experimentation was done on the assigned animals.

Primary screening of all fecal samples, using approximately $1.5 \mathrm{~g}$ faeces per sample, was performed by zinc-sulfate flotation method [8], combined with iodine staining and examined by light microscopy according to the criteria described by Nguyen et al. [13].

\section{DNA extraction and molecular analysis}

Total DNA was extracted from all microscopically positive samples using a FavorPrep Stool DNA Isolation Mini Kit (Favorgen Biotech Corporation, Changzhi, Ping-Tung, Taiwan), according to the manufacturer's instructions. The eluted DNA was dissolved in $30 \mu l$ of ultra-pure water and stored at $-20^{\circ} \mathrm{C}$.

The DNA fragments of the $\beta$-giardin $(b g)(-510 \mathrm{bp})$ and triosephosphate isomerase (tpi) ( $-530 \mathrm{bp})$ genes were amplified by polymerase chain reaction (PCR), utilizing the primer sets and protocols described by Lalle et al. [7] and Sulaiman et al. [18], respectively. Negative (without template) controls were included in each PCR batch.

The PCR products were purified using ExonucleaseI/Shrimp Alkaline Phosphatase (Exo-SAP-ITTM) (USB Corporation, Cleveland, OH, U.S.A.). Purified products were directly sequenced in a $20 \mu l$ reaction volume using the Big Dye Terminator Cycle sequencing kit version 3.1 on an automated sequencer (Applied Biosystems 3130xl, genetic analyzer), (Life Technologies Japan Ltd., Tokyo, Japan). The accuracy of data was confirmed by two-directional sequencing. The obtained sequences were blasted against the GenBank database to determine G. duodenalis genotypes/assemblages, covering a region of approximately 475 and 490 bp for bg and tpi genes, respectively. Phylogenetic trees based on both genes were constructed with the neighbor-joining algorithm using the software package MEGA, version 5.2. [19]. The statistical confidence of branching patterns was evaluated by a bootstrap test with 1,000 replications. Representative nucleotide sequences were deposited in the GenBank under the accession numbers LC 316658, LC 316659 for bg gene and LC 316660 for tpi gene. 
Table 2. Giardia duodenalis assemblages identified by sequencing of the $b g$ and $t p i$ genes in isolates from dogs in Vietnam

\begin{tabular}{ccccc}
\hline No & Isolate ID & $\begin{array}{c}\text { Age group } \\
\text { (months) }\end{array}$ & $\begin{array}{c}\text { Assemblage at } b g^{\text {a) }} \\
\text { locus }\end{array}$ & $\begin{array}{c}\text { Assemblage at } t p i^{\text {b) }} \\
\text { locus }\end{array}$ \\
\hline 1 & KH1 & $<12$ & $\mathrm{C}$ & $\mathrm{C}$ \\
2 & KH2 & $<12$ & $\mathrm{C}$ & $\mathrm{C}$ \\
3 & KH3 & $<12$ & $\mathrm{D}$ & $\mathrm{C}$ \\
4 & KH4 & $<12$ & $\mathrm{C}$ & $\mathrm{C}$ \\
5 & KH5 & $<12$ & $\mathrm{D}$ & $\mathrm{C}$ \\
6 & KH6 & $<12$ & $\mathrm{C}$ & $\mathrm{C}$ \\
7 & KH7 & $<12$ & $\mathrm{C}$ & $\mathrm{C}$ \\
8 & KH8 & $<12$ & $\mathrm{C}$ & $\mathrm{C}$ \\
9 & KH9 & $12-36$ & $\mathrm{D}$ & $\mathrm{C}$ \\
10 & KH10 & $>36$ & $\mathrm{D}$ & N/A \\
11 & DL1 & $<12$ & $\mathrm{C}$ & $\mathrm{C}$ \\
12 & DL2 & $<12$ & $\mathrm{C}$ & $\mathrm{C}$ \\
13 & DL3 & $<12$ & $\mathrm{C}$ & $\mathrm{C}$ \\
14 & DL4 & $12-36$ & $\mathrm{D}$ & N/A \\
15 & DL5 & $12-36$ & $\mathrm{C}$ & $\mathrm{C}$ \\
\hline
\end{tabular}

a) $b g=\beta$-giardin, b) $t p i=$ triosephosphate isomerase, c) N/A=No Amplification.

\section{Statistical analyses}

Statistical analyses were performed using the STATA, version 12.0 software (StataCorp LP, Lakeway Drive, College Station, TX, U.S.A.). Univariate logistic regression analysis was performed to determine the association between Giardia status and putative risk factors using Fisher's exact test or $\chi^{2}$ test. Only variables significant in the univariate analysis were further retained in the multivariate logistic regression analysis, which was undertaken to estimate the odds ratios for all such variables. The Akaike's Information Criterion was used as the calibrating parameter to select the final model. In both the univariate and multivariate analyses, associations were considered to be significant at $P<0.05$.

\section{RESULTS}

\section{Occurrence and identity of Giardia parasites}

Out of the 209 fecal samples examined by microscopy, 18 (8.6\%) samples showed the presence of Giardia cysts.

Molecularly, the expected PCR products of the $b g$ and tpi gene fragments were obtained from 15/18 and 13/18 samples, respectively (Table 2). The $b g$ gene sequences of 10 isolates (represented by sequence LC316658) were identical and showed $100 \%$ homology with those (JF422720 and AY545646) of G. duodenalis assemblage C from dogs. In addition, five sequences from 5 isolates (represented by sequence LC316659) showed 100\% homology with those of G. duodenalis assemblage D (KJ027423 and AY545647) derived from dogs. The nucleotide sequences of the tpi gene of all 13 isolates were identical (represented by sequence LC316660) and showed 99\% homology with those of G. duodenalis assemblage C (KY979493, HG970114 and KX014796). The phylogenetic trees based on the $b g$ and tpi genes are shown in Figs. 1 and 2, respectively.

\section{Risk factor analysis}

The result of the univariate logistic regression analysis for risk factors is presented in Table 1. Out of 8 predicted factors, three factors including age, gender and origins showed significant association with Giardia infection $(P<0.05)$. In contrast, factors including location, breed, clinical status, sterilized status and environmental conditions were not significantly associated with the infection.

In multivariate logistic regression analysis (Table 3), age, gender and origins of the animals were confirmed to be significantly risk factors associated with infection status. Risk factor of Giardia infection decreased with the advance in animal age. Based on the analysis, dogs under 12 months were $4.01(95 \%$ CI: 1.19, 13.41) times more likely to be infected with Giardia than those between 12-36 and $>36$ months in age. Female dogs were 6.7 (95\% CI: 1.31, 34.7) times more prone to infection than male ones. Dogs originated from stores were $3.22(95 \% \mathrm{CI}: 1.05,9.88)$ times at risk of infection than private owned dogs.

\section{DISCUSSION}

In the present study, the prevalence and identity of G. duodenalis in dogs in Vietnam was investigated. G. duodenalis cysts were detected in 18 of 209 (8.6\%) dog fecal samples examined by microscopy. This figure is similar to that previously reported in dogs from China (8.6\%) [8] and Thailand (7.9\%) [22], using the same examination method. However, it is lower than that reported in other areas using PCR or ELISA techniques including China (11-16\%) [8, 25], Trinidad and Tobago (25\%) [11], U.S.A. (15\%) [12], U.K. (21\%) [24] and Italy (57.9\%) [17]. There are several factors might contribute to differences in infection rates such as the 


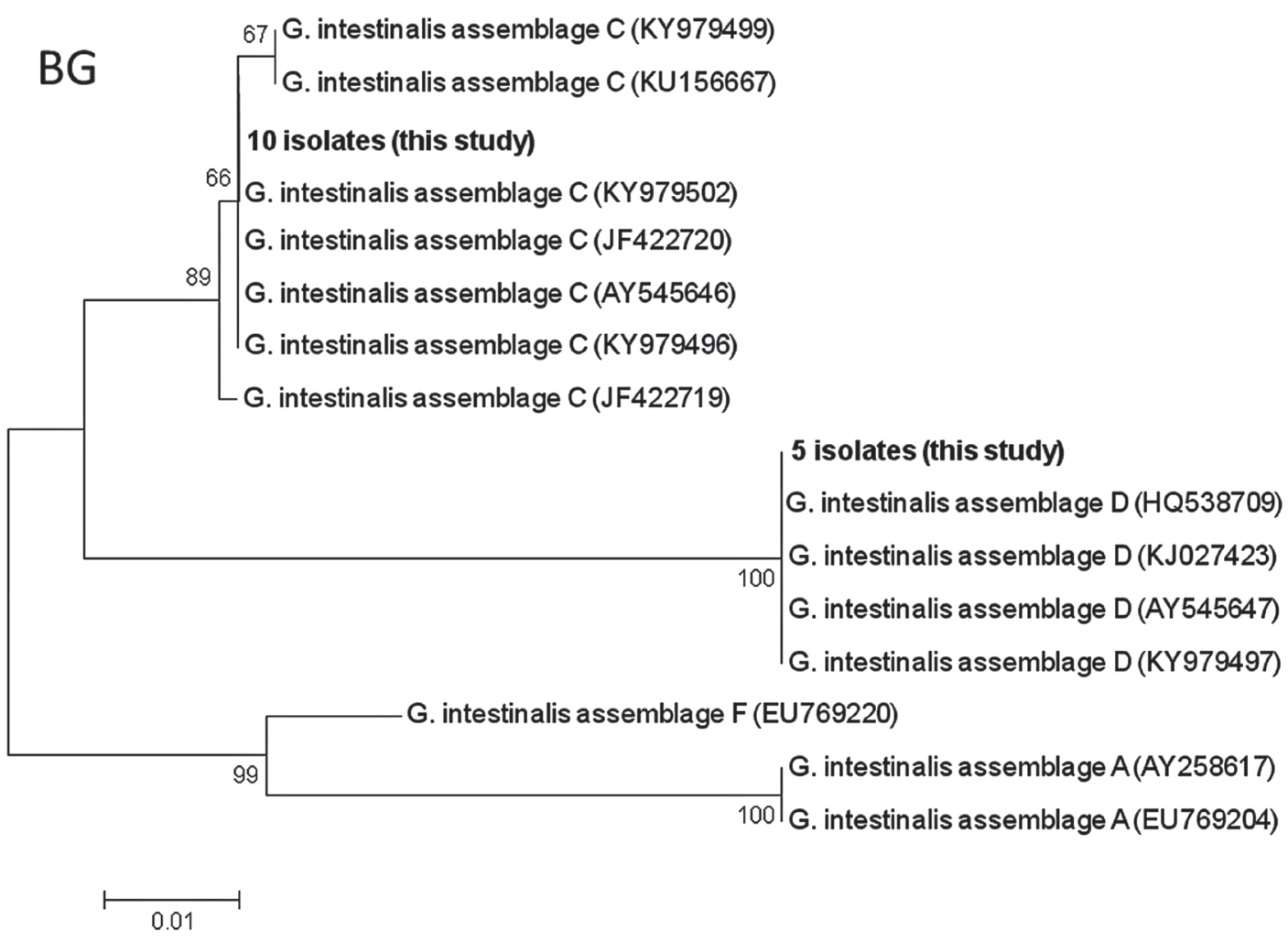

Fig. 1. Phylogenetic relationships of Giardia isolates in dogs using partial $\beta$-giardin sequences. Accession numbers are shown in parentheses.

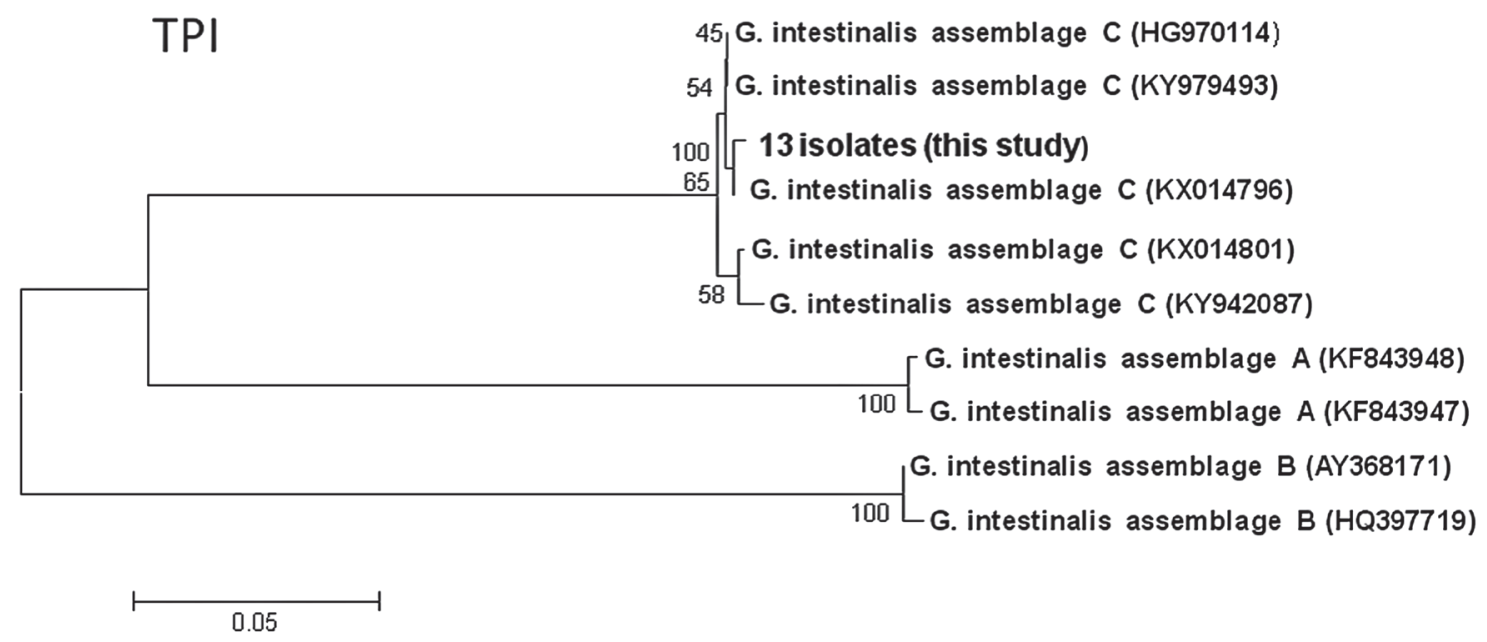

Fig. 2. Phylogenetic relationships of Giardia isolates in dogs using partial triosephosphate isomerase sequences. Accession numbers are shown in parentheses.

age of target animal population, the applied diagnostic method, the life styles of the animals and sampling schedule [11].

Statistical analysis indicated that the prevalence of Giardia significantly decreased with increasing of the age of animals, they were detected in dogs aged $>12$ months in a limited number $(6 / 136)$. In concordance, previous studies $[8,15,25]$ showed a strong correlation between the age and presence of Giardia cysts in stool samples. The same tendency was also observed in Giardia infected cats by Itoh et al. [6] in Japan. This might be linked to the possibility of frequent exposure of old animals to infection which might provide some sort of protection [15]. Thus, separating the dogs $<12$ months of age from older animals might be an effective way to reduce exposure to Giardia parasite within the dogs.

Results reported herein showed that infection of dogs with Giardia appears to vary significantly between dogs from two different origins. In agreement with results of previous reports [11,23], dogs from stores were at higher risk of infection compared to private owned ones. In fact, dogs originated from stores are usually kept in metal kennels, which might create less hygienic conditions 
Table 3. Multivariate analysis to determine factors associated with the presence of Giardia duodenalis in dogs in central Vietnam

\begin{tabular}{cccc}
\hline Variable & Odds ratio & $95 \% \mathrm{CI}$ & $P$-value \\
\hline $\begin{array}{c}\text { Age (months) } \\
<12\end{array}$ & 4.01 & $1.19-13.41$ & $0.021^{\mathrm{b})}$ \\
$12-36$ & $1^{\mathrm{a})}$ & & 0.024 \\
$\quad>36$ & 1.23 & $0.20-7.5$ & 0.819 \\
Gender & & & $0.016^{\mathrm{b})}$ \\
$\quad$ Male & $1^{\mathrm{a})}$ & & \\
$\quad$ Female & 6.7 & $1.31-34.7$ & 0.022 \\
Origins of animals & & & $0.045^{\mathrm{b})}$ \\
$\quad \begin{array}{l}\text { Private owned } \\
\text { Stores }\end{array}$ & $1^{\mathrm{a})}$ & & \\
\hline
\end{tabular}

a) Reference group, b) Overall $P$-value of variable.

and stressful situation on the animals, rendering them to be more vulnerable to the infection. In addition, the dogs in stores are not always bred in individual kennels, therefore cross infection easily occur in stores by contact with infected individuals or handling by staff. Also, a significant variation by gender group was found, however, the findings that female dogs were more prone to the infection compared to male counterparts were unexpected, and require further investigations using large sample size. In contrast, breed of dogs did not influence the prevalence of Giardia, although they showed a certain impact on the cyst shedding in other studies $[14,24]$.

In contrast to previous findings [8], the present study could not find clear association between diarrhea and infection. As mentioned by Geurden et al. [5], G. duodenalis causes chronic yet intermittent diarrhea in infected animals, making it difficult to find a correlation between this parameter and infection through a one sampling study design. Of note, several causes including nutritional and microbial factors may be implicated in occurrence of diarrhea not on the focus of the present study, and needs further investigations.

Molecular analysis in the $b g$ and tpi genes revealed presence of the G. duodenalis assemblage C and D in dogs examined. Based on tpi locus, all amplified PCR products were determined as assemblage $\mathrm{C}$ by direct sequence analysis. However, sequence results based on $b g$ locus, indicated that 10 samples were determined as assemblages $\mathrm{C}$, and 5 samples as assemblages D. The phenomenon of equivocal assignation at the assemblage level by different genes has been observed in several genotyping studies $[1,16,21]$, which was attributed to recombination process or presence of concurrent infection with more than one assemblage [16]. The result in our study was in accordance with the conclusion of dominance of assemblage C and D in dogs worldwide [3], although assemblage A and to a lesser extent, assemblage B were also detected in few surveys [2, 12].

In conclusion, this study presented a survey of risk factors and molecular characterizations of Giardia parasite in dogs in Vietnam. It showed that age, gender and origins of the animals were significantly associated with Giardia cyst shedding. Prevalence decreased with increasing age and increased in female dogs, whereas animals originated from stores were more likely to be infected with Giardia than private owned dogs. Since the assemblages C and D detected in the present study have no known zoonotic potential, risk of infection to humans is minimal. However, further studies on prevalence, genotyping and risk analysis of Giardia in humans and other livestock are warranted in order to obtain consolidated conclusion of giardiasis in Vietnam.

ACKNOWLEDGMENTS. This research is funded by Vietnam National Foundation for Science and Technology Development (NAFOSTED), under grant number: 106-NN.05-2014.10.

\section{REFERENCES}

1. Cacciò, S. M., Beck, R., Lalle, M., Marinculic, A. and Pozio, E. 2008. Multilocus genotyping of Giardia duodenalis reveals striking differences between assemblages A and B. Int. J. Parasitol. 38: 1523-1531. [Medline] [CrossRef]

2. Fava, N. M., Soares, R. M., Scalia, L. A., Cunha, M. J., Faria, E. S. and Cury, M. C. 2016. Molecular typing of canine Giardia duodenalis isolates from Minas Gerais, Brazil. Exp. Parasitol. 161: 1-5. [Medline] [CrossRef]

3. Feng, Y. and Xiao, L. 2011. Zoonotic potential and molecular epidemiology of Giardia species and giardiasis. Clin. Microbiol. Rev. 24: 110-140. [Medline] [CrossRef]

4. Geurden, T., Somers, R., Thanh, N. T., Vien, L. V., Nga, V. T., Giang, H. H., Dorny, P., Giao, H. K. and Vercruysse, J. 2008. Parasitic infections in dairy cattle around Hanoi, northern Vietnam. Vet. Parasitol. 153: 384-388. [Medline] [CrossRef]

5. Geurden, T., Vanderstichel, R., Pohle, H., Ehsan, A., von Samson-Himmelstjerna, G., Morgan, E. R., Camuset, P., Capelli, G., Vercruysse, J. and Claerebout, E. 2012. A multicentre prevalence study in Europe on Giardia duodenalis in calves, with molecular identification and risk factor analysis. Vet. Parasitol. 190: 383-390. [Medline] [CrossRef]

6. Itoh, N., Muraoka, N., Kawamata, J., Aoki, M. and Itagaki, T. 2006. Prevalence of Giardia intestinalis infection in household cats of Tohoku district in Japan. J. Vet. Med. Sci. 68: 161-163. [Medline] [CrossRef]

7. Lalle, M., Pozio, E., Capelli, G., Bruschi, F., Crotti, D. and Cacciò, S. M. 2005. Genetic heterogeneity at the beta-giardin locus among human and 
animal isolates of Giardiaduodenalis and identification of potentially zoonotic subgenotypes. Int. J. Parasitol. 35: 207-213. [Medline] [CrossRef]

8. Li, J., Zhang, P., Wang, P., Alsarakibi, M., Zhu, H., Liu, Y., Meng, X., Li, J., Guo, J. and Li, G. 2012. Genotype identification and prevalence of Giardia duodenalis in pet dogs of Guangzhou, Southern China. Vet. Parasitol. 188: 368-371. [Medline] [CrossRef]

9. Li, W., Li, Y., Song, M., Lu, Y., Yang, J., Tao, W., Jiang, Y., Wan, Q., Zhang, S. and Xiao, L. 2015. Prevalence and genetic characteristics of Cryptosporidium, Enterocytozoon bieneusi and Giardia duodenalis in cats and dogs in Heilongjiang province, China. Vet. Parasitol. 208 : $125-134$. [Medline] [CrossRef]

10. Liu, A., Zhang, X., Zhang, L., Wang, R., Li, X., Shu, J., Zhang, X., Shen, Y., Zhang, W. and Ling, H. 2012. Occurrence of bovine giardiasis and endemic genetic characterization of Giardia duodenalis isolates in Heilongjiang Province, in the Northeast of China. Parasitol. Res. 111: 655-661. [Medline] [CrossRef]

11. Mark-Carew, M. P., Adesiyun, A. A., Basu, A., Georges, K. A., Pierre, T., Tilitz, S., Wade, S. E. and Mohammed, H. O. 2013. Characterization of Giardia duodenalis infections in dogs in Trinidad and Tobago. Vet. Parasitol. 196: 199-202. [Medline] [CrossRef]

12. Munoz, J. and Mayer, D. C. 2016. Toxoplasma gondii and Giardia duodenalis infections in domestic dogs in New York City public parks. Vet. J. 211: 97-99. [Medline] [CrossRef]

13. Nguyen, S. T., Fukuda, Y., Nguyen, D. T., Tada, C. and Nakai, Y. 2016. Prevalence and first genotyping of Giardia duodenalis in beef calves in Vietnam. Trop. Anim. Health Prod. 48: 837-841. [Medline] [CrossRef]

14. Pallant, L., Barutzki, D., Schaper, R. and Thompson, R. C. 2015. The epidemiology of infections with Giardia species and genotypes in well cared for dogs and cats in Germany. Parasit. Vectors 8: 2. [Medline] [CrossRef]

15. Pipia, A. P., Varcasia, A., Tamponi, C., Sanna, G., Soda, M., Paoletti, B., Traversa, D. and Scala, A. 2014. Canine giardiosis in Sardinia Island, Italy: prevalence, molecular characterization, and risk factors. J. Infect. Dev. Ctries. 8: 655-660. [Medline] [CrossRef]

16. Santín, M., Cortés Vecino, J. A. and Fayer, R. 2013. A large scale molecular study of Giardia duodenalis in horses from Colombia. Vet. Parasitol. 196: 31-36. [Medline] [CrossRef]

17. Simonato, G., Frangipane di Regalbono, A., Cassini, R., Traversa, D., Beraldo, P., Tessarin, C. and Pietrobelli, M. 2015. Copromicroscopic and molecular investigations on intestinal parasites in kenneled dogs. Parasitol. Res. 114: 1963-1970. [Medline] [CrossRef]

18. Sulaiman, I. M., Fayer, R., Bern, C., Gilman, R. H., Trout, J. M., Schantz, P. M., Das, P., Lal, A. A. and Xiao, L. 2003. Triosephosphate isomerase gene characterization and potential zoonotic transmission of Giardia duodenalis. Emerg. Infect. Dis. 9: 1444-1452. [Medline] [CrossRef]

19. Tamura, K., Peterson, D., Peterson, N., Stecher, G., Nei, M. and Kumar, S. 2011. MEGA5: molecular evolutionary genetics analysis using maximum likelihood, evolutionary distance, and maximum parsimony methods. Mol. Biol. Evol. 28: 2731-2739. [Medline] [CrossRef]

20. Thompson, R. C., Palmer, C. S. and O'Handley, R. 2008. The public health and clinical significance of Giardia and Cryptosporidium in domestic animals. Vet. J. 177: 18-25. [Medline] [CrossRef]

21. Traub, R. J., Monis, P. T., Robertson, I., Irwin, P., Mencke, N. and Thompson, R. C. 2004. Epidemiological and molecular evidence supports the zoonotic transmission of Giardia among humans and dogs living in the same community. Parasitology 128: 253-262. [Medline] [CrossRef]

22. Traub, R. J., Inpankaew, T., Reid, S. A., Sutthikornchai, C., Sukthana, Y., Robertson, I. D. and Thompson, R. C. 2009. Transmission cycles of Giardia duodenalis in dogs and humans in Temple communities in Bangkok--a critical evaluation of its prevalence using three diagnostic tests in the field in the absence of a gold standard. Acta Trop. 111: 125-132. [Medline] [CrossRef]

23. Uehlinger, F. D., Greenwood, S. J., McClure, J. T., Conboy, G., O’Handley, R. and Barkema, H. W. 2013. Zoonotic potential of Giardia duodenalis and Cryptosporidium spp. and prevalence of intestinal parasites in young dogs from different populations on Prince Edward Island, Canada. Vet. Parasitol. 196: 509-514. [Medline] [CrossRef]

24. Upjohn, M., Cobb, C., Monger, J., Geurden, T., Claerebout, E. and Fox, M. 2010. Prevalence, molecular typing and risk factor analysis for Giardia duodenalis infections in dogs in a central London rescue shelter. Vet. Parasitol. 172: 341-346. [Medline] [CrossRef]

25. Yang, D., Zhang, Q., Zhang, L., Dong, H., Jing, Z., Li, Z. and Liu, J. 2015. Prevalence and risk factors of Giardia doudenalis in dogs from China. Int. J. Environ. Health Res. 25: 207-213. [Medline] [CrossRef]

26. Yason, J. A. and Rivera, W. L. 2007. Genotyping of Giardia duodenalis isolates among residents of slum area in Manila, Philippines. Parasitol. Res. 101: 681-687. [Medline] [CrossRef] 